\title{
PROJECTING LONG TERM MEDICAL SPENDING GROWTH
}

\author{
Christine Borger, Thomas F. Rutherford, Gregory Y. Won*
}

Abstract: This paper presents a dynamic general equilibrium model of the U.S. economy and the medical sector in which the adoption of new medical treatments is endogenous and the demand for medical services is conditional on the state of medical technology. The model provides a straightforward explanation of the paradox that the demand for medical services is rising, even though medical price inflation is faster than non-medical price inflation. We use this model to prepare 75-year medical spending projections and compare our projections with forecasts based on an older method widely used by government and private actuaries and economists. As part of this comparison, we compute the implications for the medical share of total output and the financial status of the Medicare program. Our baseline forecast predicts slower health spending growth in the long run relative to the older projection methodology. Also, while the 75-year actuarial deficit of the Medicare program implied by our model is similar to that implied by the older methodology, our results suggest that over time our model would predict a lower deficit relative to the older methodology.

JEL Classification: C68, H51, I11

Key Words: General equilibrium, long term medical spending, Medicare actuarial balance.

\footnotetext{
*Won: Corresponding author. E-mail: gregorywon@comcast.net. Address: 3603 Southside Avenue, Phoenix, MD 21131. Phone: 410-236-0017. Rutherford: Charles River Associates International, Inc. (CRAI). E-mail: tom@mpsge.org. Address: 4829 Northgate Drive, Ann Arbor, MI 48103-9770. Borger and Won: Office of the Actuary, Centers for Medicare and Medicaid Services, U.S. Department of Health and Human Services. The views expressed are those of the authors and do not represent the views of CRAI or the Centers for Medicare and Medicaid Services. We are indebted to Charles Ballard, Michael Chernew, David Cutler, Charles Jones, Harry Kelejian, Margaret McCarthy, and Joseph Newhouse for their invaluable comments.
} 


\section{Introduction}

The last century has witnessed tremendous advances in medical technology that have vastly improved both the length and quality of life. Associated with the expansion in the array of medical treatments, however, has been the relentless growth of medical spending as a share of total final demand. Since the end of the Second World War per capita medical care expenditures have grown on average two-and-a-half percentage points faster per year than per capita GDP. ${ }^{1}$ In 1948 national health expenditures (NHE) accounted for about 4 percent of GDP, by 2004 the NHE share of GDP was 16 percent, and by 2015 it is projected to approach 20 percent. ${ }^{2}$ While it could be argued that the increasing medical share of GDP simply reflects consumer preferences for better health, these trends raise long run concerns, in particular with respect to the government's future medical spending obligations under current law, and the private sector's ability to provide health care coverage.

In recent years, researchers have explored the long run consequences if the historical pattern of health spending growth continues unabated [e.g., Chernew, et al. (2003), Follette and Sheiner (2005)]. However, these investigations typically have assumed that long run medical spending growth, net of age and gender effects, is simply a fixed percentage faster than GDP growth. This assumption is also the basis for the federal government's long term Medicare projections. (Hereafter we use what has become common terminology and refer to this assumption as $G D P+X$, where $X$ denotes the differential between medical spending growth and GDP growth.) Previously, only a handful of studies [Warshawski (1999), Jones (2004) and Hall

\footnotetext{
${ }^{1}$ Technical Review Panel on the Medicare Trustees Reports, Review of Assumptions and Methods of the Medicare Trustees' Financial Projections, Centers for Medicare and Medicaid Services (formerly Health Care Financing Administration), December 2000, p 29.

${ }^{2}$ Borger, et al., "Health Spending Projections Through 2015: Changes on the Horizon," Health Affairs, Web Exclusive, February 22, 2006.
} 
and Jones (2005)] had attempted to put long run medical spending projections in the context of households' responses to changing economic conditions.

Alternative assumptions about the long-range medical-GDP growth differential have large implications for policy evaluation. By 2050 under GDP + 1, NHE will be approximately 33 percent of GDP, and federal spending will be 23.4 percent of GDP, with federal Medicare and Medicaid spending accounting for about one-half of that total (11.5 percent of GDP), nearly double Social Security spending (6.2 percent). However, under GDP + $2.5 \mathrm{NHE}$ will be about 50 percent of GDP in 2050, federal spending will be 32.9 percent of GDP, and federal Medicare and Medicaid spending would account for 21.3 percent of GDP, more than triple Social Security spending. ${ }^{3}$

This paper presents a dynamic model of the U.S. economy and the medical sector, in which the adoption of new medical treatments is endogenous. We use this model to prepare long-run medical spending projections and compare our projections with forecasts based on the $G D P+X$ methodology. As part of this comparison, we compute the implications for the health share of total output and the financial status of the Medicare program. Our intermediate forecast predicts slower health spending growth in the long run, relative to the current methodology. Also, while the 75-year actuarial deficit of the Medicare program implied by our model is similar to that implied by the older methodology, our results suggest that over time our methodology would predict a lower deficit relative to the older methodology.

\footnotetext{
${ }^{3}$ Federal spending projections: Testimony of Douglas Holtz-Eakin, Director, Congressional Budget Office, before the Senate Committee on the Budget, "The Economic Costs of Long-Term Federal Obligations," February 16, 2005. Note these figures include only the federal share of the joint federal/state Medicaid program. NHE projections: authors estimates based on updated calculations from the 2000 Medicare Technical Review Panel.
} 


\section{Background}

Medical care is virtually unique among major categories of consumption in that for many decades real medical consumption has grown faster than total consumption, even though relative medical prices have been rising faster than other prices (Table 1). There is broad agreement among health economists that the primary explanation for this paradox is technological change. ${ }^{4}$ Newhouse (1992) concludes that after accounting for non-technology factors, such as income growth, health insurance and changes in the composition of the population, there is a large residual-ranging from one-half to three-quarters of the increase in medical spending between 1940 and 1990 — of unexplained health spending growth, the bulk of which is related to technological innovation. Cutler (1995), using a similar methodology, finds that the technology residual is approximately 50 percent. Peden and Freeland (1998) conclude that about two-thirds of per capita medical spending growth results from cost-increasing advances in medical technology.

Medical technological change has two dimensions, although different researchers have proposed several variations in terminology. Newhouse (1978) describes these dimensions in terms of "process-innovation," which makes the production process more efficient; and "product innovation," which refers to the development of new medical treatments. Product-innovation, in turn, can be expenditure-decreasing or expenditure-increasing [Weisbrod (1991)]. Expendituredecreasing innovations reduce treatment costs; e.g., the development of a polio vaccine virtually eliminated the costs associated with treating a life-long crippling disease. Expenditure-

\footnotetext{
${ }^{4}$ Victor Fuchs polled 46 leading health economics, 44 eminent economic theorists, and 42 practicing physicians. Eighty-one percent of the health economists agreed with the statement: "The primary reason for the increase in the health sector's share of GDP over the past 30 years is technological change in medicine." However, only 68 percent of the practicing physicians agreed with this statement, and only 37 percent of the economic theorists. Victor R. Fuchs, "Economics, Values, and Health Care Reform," American Economic Review, 86:1-24, 1996.
} 
increasing innovations raise costs either by introducing therapies for previously untreatable conditions or by providing more expensive alternatives to existing therapies (with presumably greater health benefits), e.g., a new procedure that expands surgical intervention to a larger population of patients. ${ }^{5}$

In summary, the demand for medical care is a byproduct of the demand for health, and therefore conditional on the state of medical knowledge. This framework gives a straightforward way to explain the paradox illustrated in Table 1. Simply put: over time innovation enables physicians to cure more diseases so the demand for physician services increases. However, the degree to which medical expenditures rise relative to income depends on preferences for health vis-à-vis non-medical consumption, and on the degree to which new treatments can be substituted for existing ones.

\section{The Model}

\subsection{Single Period Submodel}

We consider an economy in which market output consists of medical goods and services, $M$, and non-medical goods and services, $X$. These are produced using two primary factors of production: labor, $L$, and capital $K$. In the spirit of Grossman (1972) we introduce the concept of health, $H$, as a private, non-market commodity in order to provide a concrete framework for

\footnotetext{
${ }^{5}$ Chernew, et al. (1998) describe an equivalent dichotomy in which a new technology either requires more resource use ("complementary services") or leads to a reduction in resource use ("substitutive services"). Cutler and McClellan (2001) also refer to "treatment substitution effects, where a new technology substitutes for an older technology in the therapy of established patients; and "treatment expansion effects," where a new technology leads to more people being treated. In some cases, a new technology produces both substitution and expansion effects. Cutler and McClellan (1998) cite angioplasty as an example. The substitution of angioplasty for bypass surgery significantly reduced the cost to treat some patients with acute myocardial infarction (AMI), but overall the introduction of the procedure "added significantly to the cost of AMI treatment by extending the intensive interventions to a larger segment of AMI patients." David M. Cutler and Mark B. McClellan. "What is Technological Change?" in Inquiries in the Economics of Aging, ed. David W. Wise, National Bureau of Economic Research Project Report. MIT Press, 1998.
} 
representing the relationship between medical innovation and the demand for medical goods and services. ${ }^{6}$ We can then represent the consumer problem as a conventional three good demand system:

$$
\begin{aligned}
U(\ell, H, C)= & {\left.\left[\alpha_{u}^{\frac{1}{\sigma_{u}}} \ell^{\frac{\sigma_{u}-1}{\sigma_{u}}}+\left(1-\alpha_{u}\right)^{\frac{1}{\sigma_{u}}}\left[(H-\bar{H})^{\alpha}(C-\bar{C})^{1-\alpha}\right]^{\sigma_{u}-1}\right]^{\frac{\sigma_{u}}{\sigma_{u}}}\right]^{\frac{\sigma_{u}-1}{u}} } \\
& \text { s.t. } p_{H} H+p_{X} C=p_{L}(\bar{L}-\ell)+p_{Z} Z+R
\end{aligned}
$$

Where:

$\bar{L}$ represents the time endowment,

$\ell$ represents leisure demand (labor supply is $\bar{L}-\ell$ ),

$C$ represents consumption of non-medical goods and services,

$H$ represents health,

$\bar{C}$ and $\bar{H}$ are non-medical and health consumption minima

$R$ is capital income net savings,

$Z$ is the state of medical knowledge,

$p_{L}$ is the net wage,

$p_{X}$ is the price of non-medical goods and services,

$p_{H}$ is the unobserved shadow price of health, and

$\alpha, \alpha_{u}, \sigma_{u}$ are parameters.

\footnotetext{
${ }^{6}$ Our model also incorporates age and gender factors to account for changes in per capita medical consumption induced by the aging of the population. Following the convention used by government actuaries, our demographic factors are based on fixed-weighted medical consumption indices, where the weights are determined from medical consumption patterns for a given reference year. Specifically, the weights for our indices are taken from the 1999 Medical Expenditure Panel Survey (MEPS). For reasons that are discussed later, we suppress demographic effects at this point, and reintroduce them in our calculations of the national health expenditure share of GDP and the actuarial balance of the Medicare program.
} 
Health is produced using a combination of medical goods and services, $M$, and a non-market input representing the current state of medical knowledge, $Z$. The state of medical knowledge is a non-traded public good which evolves autonomously over time at a constant geometric growth rate.

$$
H(Z, M)=\left[\alpha_{h}^{\frac{1}{\sigma_{h}}} Z^{\frac{\sigma_{h}-1}{\sigma_{h}}}+\left(1-\alpha_{h}\right)^{\frac{1}{\sigma_{h}}} M^{\frac{\sigma_{h}-1}{\sigma_{h}}}\right]^{\frac{\sigma_{h}}{\sigma_{h}-1}}
$$

$\alpha_{h}$ is the reference period technology share of health output. A more intuitive interpretation of this parameter, however, is that it also is a measure of the strength of preferences for health. This follows since, for a given level of medical input, $\alpha_{h}$ determines the reference period level of health output which equals the reference period demand for health in equilibrium. As $\alpha_{h}$ approaches zero, improvements in health associated with new medical technologies do not affect the demand for medical care. In this case, the model cannot provide a technology-based explanation for the medical sector's growing share of output.

$\sigma_{h}$ is the elasticity of substitution between medical knowledge and medical care inputs in the production of health. If $\sigma_{h}=0$, then new technologies cannot be substituted for medical care input. In this case, health benefits can only be attained if new medical knowledge is combined with more medical care; that is, new technology is purely cost-increasing. On the other hand, as $\sigma_{h} \rightarrow \infty$ medical technology and medical care inputs are interchangeable in the production of health. If all other variables are held constant, changes in $\sigma_{h}$ affect the speed with which the steady-state medical share of output is reached.

The supply side of the model then consists of profit maximization by two types of firms: 
1. Medical goods and services

$$
\begin{gathered}
\max p_{M} M-p_{X} X_{M}-p_{L}\left(1+t_{L}\right) L_{M}-p_{K}\left(1+t_{K}\right) K_{M} \\
\text { s.t. } \quad M=\min \left(\alpha_{m} X_{M},\left(1-\alpha_{m}\right)\left(K_{M}^{\alpha_{v}} L_{M}^{1-\alpha_{v}}\right)\right)
\end{gathered}
$$

Where $X_{M}$ represents non-medical inputs used in the production of medical care; $L_{M}$ and $K_{M}$ are medical sector labor and capital inputs, respectively; $t_{L}$ and $t_{K}$ are the tax rates on labor and capital, respectively; and $\alpha_{m}$ and $\alpha_{v}$ are production function parameters that are calibrated from U.S. input-output data.

2. Non-medical output

$$
\begin{gathered}
\max X-p_{L}\left(1+t_{L}\right) L_{X}-p_{K}\left(1+t_{K}\right) K_{X} \\
\text { s.t. } \quad X=K_{X}^{\alpha_{X}} L_{X}^{1-\alpha_{X}}
\end{gathered}
$$

Market prices are determined at the levels which clear output and factor markets:

$$
\begin{gathered}
L_{X}+L_{M}=\bar{L}-\ell \\
K_{X}+K_{M}=\bar{K} \\
X=X_{M}+C+I
\end{gathered}
$$

The government sector consumes only non-medical goods and services and this activity is funded through a lump-sum tax. The model incorporates the assumption that total government consumption is approximately 20 percent of GDP, a figure that is consistent with recent 
experience. Transfer payments are not directly modeled. Thus, the model does not focus on the financing issues associated with the public provision of medical care services. Closure of the model involves specification of a level of investment, $I$, and a level of non-wage income.

$$
R=p_{K} \bar{K}+t_{L} p_{L} \bar{L}+t_{K} p_{K} \bar{K}-I
$$

Our model gives a stylized representation of the production of and demand for health, where health is represented by a single index. As such it has several limitations. First, health has many dimensions; for example, longevity, mobility, freedom from pain or discomfort, mental/psychological health, etc. Our use of an index to represent these dimensions finds precedent in the substantial literature on medical cost-effectiveness analysis in which the benefits of medical care are typically measured in terms of years-of-life (YOL) or quality adjusted life years (QALY). There is debate, however, over the usefulness of these concepts. YOL, for instance, ignores other non-survival related reasons for medical consumption and there are conceptual and measurement problems associated with QALY [Meltzer (2001)].

Second, our model glosses over the fact that the production of health has many inputs in addition to medical care such as time invested in exercise, diet, and abstinence from risky or unhealthy, but pleasurable, activities. Presumably, the rational consumer chooses between healthy and unhealthy current consumption taking into consideration discounted future adverse health and financial consequences [Triplett (2001)]. Also, the model does not consider marketdriven innovations in non-medical sectors that could affect medical consumption-for example, the development of fat-substitutes in prepared foods that could lower the prevalence of obesityrelated diseases. 
Third, geographic disparities in the utilization of medical treatments suggest that the production of health in the United States is characterized by inefficiency [Wennberg et al. (2002)]. For example, in regions where there are more physicians and hospital beds per capita, there could be incentives for health care providers to induce demand [Cromwell and Mitchell (1986), Rochaix (1989), Rizzo and Blumenthal (1996)].

Fourth, our model does not have an explicit representation of the household insurance decision. Although the type of health insurance coverage people choose is a very important determinant of medical care consumption in the short run, long run changes in the institutions of medical care financing reflect underlying preferences for health versus non-medical consumption [Getzen (2000)]. The model does not identify the precise mechanisms through which the market will restrain spending growth—some of the mechanisms may not yet exist—but posits that long run spending growth must be consistent with consumer desires to purchase things other than medical care. ${ }^{7}$

\subsection{The Intertemporal Model}

The extension of this model to an intertemporal framework involves application of a time subscript to all of the variables and extending the consumer's problem to include a choice of the consumption path over time. Goods and factor prices are dated and all prices are interpreted as present values. At any point in time, there is a shadow value for health, and health enters into consumer preferences along with other goods.

The response of savings and investment by private households is based on the logic of the Ramsey growth model in which $C_{t}, H_{t}$ and $\ell_{t}$ solve:

\footnotetext{
${ }^{7}$ In theory insurance affects the demand for medical care through two channels: (1) the direct effect on perceived out-of-pocket costs at the point of purchase, and (2) the indirect effect on the rate of technological innovation.
} 


$$
\max \sum_{t=0}^{\infty}\left(\frac{1}{1+\rho}\right)^{t} \frac{U\left(\ell_{t}, H_{t}, C_{t}\right)^{1-\theta}-1}{1-\theta}
$$

Subject to the intertemporal budget constraint:

$$
\sum_{t=0}^{\infty}\left(p_{X t} C_{t}+p_{H t} H_{t}\right)=p_{K 0} K_{0}+\sum_{t=0}^{\infty}\left(p_{L t}\left(L_{t}-\ell_{t}\right)+p_{Z t} Z_{t}+T_{t}\right)
$$

in which $T_{t}$ is the present value of labor and capital tax revenue in the associated period. In the Ramsey framework the capital stock evolves through depreciation and investment:

$$
K_{t}=\left(1-\delta_{K}\right) K_{t-1}+I_{t-1}
$$

and markets for primary factors and output clear in each period. (Figure 1 shows a schematic representation of the model.)

\section{Calibration}

Calibration of the model involves assigning values to the model parameters and in most cases is based on the 1977 and 1992 U.S. input-output data (exogenous parameters are listed in Table 2). ${ }^{8}$ However, the model simulations depend primarily on three key unobserved parameters: $\alpha_{h}, \sigma_{h}$, and $g_{z}$, the growth rate of medical knowledge. In this section we use three methods to narrow the range of possible values for these key parameters: (i) calibrating the model to a reference period, (ii) reconciling the parameter values with demand elasticity estimates from the literature, and (iii) estimates developed from a time series method.

\footnotetext{
${ }^{8}$ Detailed explanations of the calibration process for dynamic models, as well as examples, can be found at Rutherford's website: mpsge.org.
} 


\subsection{Reference Period Calibration}

Although the rate of medical innovation cannot be directly measured, we can infer what it must have been in order for the model to replicate the pattern of medical care consumption (which we measure using the CMS personal health care, $\mathrm{PHC}$, consumption estimate) for a specified reference period, given a particular $\left(\alpha_{h}, \sigma_{h}\right)$-pair. ${ }^{9}$ To increase the model's leverage our reference period spans 1977-2015, including both historical data (1977-2004) and the 10year forecast from the Centers for Medicare and Medicaid Services (CMS).

As a first step, we restricted the ranges of $\alpha_{h}$ and $\sigma_{h}$ by excluding those values for which calibration is infeasible. This exercise indicates that feasible $\left(\alpha_{h}, \sigma_{h}\right)$-pairs are in the range of $0.6<\alpha_{h}<1.0$, and $0.0<\sigma_{h}<0.6$. The results generally affirm two common-sense notions about medical care consumption: first, preferences for health are relatively strong and new medical technology tends to be cost-increasing. If the demand for health is too weak ( $\alpha_{h}$ "too small") or if new technology is too easily substitutable for medical care inputs in the production of health ( $\sigma_{h}$ "too large"), then the model cannot replicate the historical pattern of medical spending growth regardless of the rate of technological innovation. The results of the calibration exercise are illustrated in Figure 2, which shows PHC/GDP share contours - each line represents the locus of combinations of $\alpha_{h}$ and $\sigma_{h}$ that produce a given 2100 PHC-GDP share (net of growth attributable to demographic effects).

\footnotetext{
${ }^{9}$ In our paper, we have been careful to make a distinction between medical care and health. Medical care represents the goods and services used to treat illness; health is the output produced by inputs of medical care and medical knowledge (and possibly other inputs). In the official government statistics, our concept of medical care is referred to as "personal health care" (PHC) consumption. PHC, as measured by the Centers for Medicare and Medicaid Services, represents "therapeutic goods and services rendered to treat or prevent a specific disease or condition in a specific person." National health expenditures (NHE) equals PHC plus government public health activity, program administration (including the net cost of private health insurance), and medical sector investment.
} 


\subsection{Reconciliation with Empirical Research}

\subsubsection{Price Elasticity}

Without any other constraints, the model can generate a wide range of medical spending forecasts. For example, Figure 3 shows the ratios of medical-to-GDP growth under alternative assumptions about the cost expansion effect of medical innovation. When new medical treatments are perfectly cost-increasing $\left(\sigma_{h}=0\right)$ the model produces a kinked time path in which medical share growth rises at roughly a constant rate, and then abruptly levels off. This pattern mimics the Jones (2003) model: new treatments are fully adopted up to the share that represents society's maximum willingness to transfer income from healthy people to sick people (via private insurance or public transfer payments). Conversely, if future medical technologies are substitutive, then medical expenditures could fall as a share of final demand.

We can further narrow the range of model predictions by reconciling the key parameters with empirical demand elasticity estimates from the literature. The reference period price elasticity of medical care in our model, $\eta_{m}$, is approximated by a function of $\alpha_{h}$ and $\sigma_{h}$ :

$$
\eta_{m}=-\alpha_{h} \sigma_{h}-\left(1-\alpha_{h}\right)
$$

Unfortunately, the range of demand elasticity estimates is quite large, ranging from less than (in absolute value) -0.1 to more than -0.8 .

Although now over thirty years old, results from the government funded RAND Health Insurance Experiment (HEI) are highly regarded among studies of medical care demand, as the experiment's design mitigated many of the adverse selection issues associated with health insurance. Based on the RAND HEI results, Manning et al. (1987) calculated price elasticities based on the average coinsurance rate. Their methodology yielded an elasticity estimate for total 
medical services of -0.10 for the $0-25$ percent coinsurance range and -0.14 for the $25-95$ percent range. Manning concludes that "[medical care] price elasticities for a constant coinsurance policy are in the -0.1 to -0.2 range." 10 This result is consistent with the lower range of findings from work that is not based on randomized experiments. Put another way, the RAND HIE appears to suggest parameter values for our model that are in the ranges of $0.0 \leq \sigma_{h} \leq 0.2$ and 0.8 $\leq \alpha_{h}<1$

However, for our purposes, the RAND-based results should be interpreted with caution. In particular, it is not clear that these estimates are consistent with the assumptions embodied in our model. Within the model, a single consumer represents the preferences of the populations as a whole. The RAND HIE may not be representative of the general population since it involved people in only six cities, and differences in medical care use patterns have been observed across the country. Furthermore, given its six-year scope, it is likely that the study does not fully account for technological and institutional changes (such as the emergence of managed care) which may affect elasticities.

In their survey of international comparisons of health expenditures, Gerdtham and Jonsson (2000) identified two studies in which demand elasticities were estimated. Based on a sample of 22 OECD countries in 1985, Gerdtham and Jonsson (1991) reported a price elasticity of -0.84. Milne and Molana (1991) estimated a price elasticity of -0.73 using data from 1980 and 1985 for a sample of 11 European Community countries. Though these studies appear to justify the use of higher price elasticities, Gerdtham and Jonsson cite a number of problems associated with international comparisons including: the reliability of cross-national data, small sample size, the imposition of homogenous relationships across countries (e.g., in preferences and

\footnotetext{
${ }^{10}$ Willard G. Manning, et al, "Health Insurance and the Demand for Medical Care: Evidence from a Randomized Experiment,” American Economic Review. June.1987. p 268.
} 
production technologies), and measurement problems associated with purchasing power parity. Moreover, there is a fundamental question of how well these results relate to the U.S. experience.

Table 3 shows a survey of U.S. and international results. The simple average of these studies is approximately -0.4 , but there is substantial variability in the estimates. The literature average is consistent with model parameters in the ranges $0.0 \leq \sigma_{h} \leq 0.4$ and $0.6 \leq \alpha_{h}<1.0$.

\subsubsection{Income Elasticity}

While our model permits alternative assumptions about income elasticity, our baseline simulations assume unit income elasticity. Table 4 shows results from selected studies [taken from Getzen (2000) and Gerdtham and Jonsson (2000)]. In evaluating these results there are two broad issues to consider: (1) the level of aggregation used in the study, and (2) the vintage of the study. "Micro" studies based on individual observations find only modest income effects. This follows since insurance coverage limits the effect of an individual household's income constraint on medical consumption. In his survey of income elasticity estimates, Getzen (2000) concludes that most of the variation in medical spending is associated with differences in health status and that income elasticities are "small or negative." On the other hand, national level aggregate consumption is constrained in the national income, and individual differences in health status are averaged out. "At the macro level, studies of national expenditures consistently show income elasticities greater than 1.0 , with $90+\%$ of cross-sectional and time series variation explainable by differences in per capita income, and differences in health status as having negligible effects...” [Getzen (2000), p 264.]

Studies based on international data typically show income elasticities at one or greater than one. Gerdtham and Jonsson dichotomize these studies into two broad groups: first- 
generation studies that are based on "international cross-section data for a single year (or selected years)," and second-generation studies that use panels of countries "each with a relatively long time series of annual data." The latter studies, owing to larger sample sizes, are generally more sophisticated in that they control for effects-e.g., country- and time-specific effects, institutional characteristics, and other factors such as tobacco consumption — that might otherwise result in inconsistent estimates. Table 4 shows that, generally first-generation studies report income elasticities greater than one, and second-generation studies report income elasticities at one or slightly less than one.

\subsection{Unobserved Components Model}

Under the assumptions described in section 3, the demand for medical care is:

$$
M=\alpha\left(1-\alpha_{h}\right) \frac{I}{P_{U}}\left(\frac{P_{U}}{P_{H}}\right)\left(\frac{P_{H}}{P_{M}}\right)^{\sigma_{h}}
$$

Where $I$ is income and $P_{U}$ is the price index of utility. Direct estimation of $\alpha, \alpha_{h}$, and $\sigma_{h}$ is made difficult by the fact that we do not have measures for the price of health or the stock of medical knowledge from which it is produced. In this section we use an unobserved components model (UCM) to derive estimates of the key unobserved parameters. Specifically, we express equation 13 in terms of natural logarithms and rearrange to derive equation 14.

$$
\ln \left(\frac{M_{t}}{I_{t} / P_{U}}\right)=\mu_{t}+\delta \ln \left(\frac{P_{U t}}{P_{M t}}\right)+\varepsilon_{t}
$$


Where we interpret $\mu_{t}$ as:

$$
\mu_{t}=\ln \left[\alpha\left(1-\alpha_{h}\right)\right]+\left(1-\sigma_{h}\right) \ln \left(\frac{P_{U t}}{P_{H t}}\right)
$$

Equations 14 and 15 imply that the medical share of income is a function of: (i) the relative price of medical care, and (ii) $\mu_{t}$ an unobserved component embodying the price health, which in turn reflects medical innovations that change the relationship between the dependent and independent variables over time. We estimate the unobserved component and independent variable coefficients using the Kalman filter. With prices normalized to 1.0 in the reference period:

$$
\mu_{1}=\ln \left[\alpha\left(1-\alpha_{h}\right)\right]
$$

After the initial period, $\mu_{t}$ follows a trend that reflects health price inflation relative to the overall inflation.

The time series approach described above gives an estimate of the health production function elasticity of substitution: $\sigma_{h}=\delta$. On the other hand, $\alpha_{h}$ cannot be directly determined from the model estimation. However, equation 16 implies a relation between $\alpha$ and $\alpha_{h}$ that can be used, together with other information, to calculate an estimate of $\alpha_{h}$. In particular, although we cannot measure $Z$, the level of medical knowledge, our assumption about $\alpha_{h}$, the reference period technology share of health, determines $Z$ and hence determines the reference period level of health output. This, in turn, determines the reference period health share of consumption, $\alpha$. So one method to construct estimates of $\alpha$ and $\alpha_{h}$ is to select those combinations that 
simultaneously solve equation 16 , and the model utility and production functions for some base period.

In our baseline estimate of equation 14, medical care is measured in terms of real per capita personal health care spending in 1960 dollars (NPHC60); income is measured in terms of real per capita GDP (MNGDP60); and $P_{U}$, the price index associated with overall consumption, is measured by the GDP implicit price deflator (PGDP). ${ }^{11}$ The price of medical care is measured using the CMS personal health care price index (PPHC). The results are shown in Table 5 (equation 1) which gives estimates for $\left(\alpha_{h}, \sigma_{h}\right)$ of $(0.89,0.39)$-values that are consistent with a medical price elasticity that is approximately in the middle of the range of published estimates.

The results, however, are sensitive to different income concepts. Estimating equation 14 using per capita real disposable income (MNDPI60) yields a similar estimate for $\sigma_{h}$, but the computed value of $\alpha_{h}$ is 0.52 (a value for which our model cannot replicate the reference calibration period regardless of the value of $\sigma_{h}$ ). For comparison purposes, Table 5 also shows the results when the medical demand model is expressed in terms of the real per capita level of medical spending, rather than the ratio of medical spending to income. Notably, the estimate of the health production function elasticity of substitution is consistent across equations.

\section{Simulations}

To reiterate, although the rate of medical innovation cannot be directly measured, we can infer what it must have been in order for the model to generate the historical pattern of medical

${ }^{11}$ All variables are in natural logarithms and all real values are rebased to 1960, the earliest year for which CMS has developed estimates for personal health care expenditures. We use a five-year trailing average of real per capita GDP. Changes in medical spending typically lag changes in income in part due to the effect of health insurance underwriting cycle. 
spending growth, given a particular $\left(\alpha_{h}, \sigma_{h}\right)$-pair. Based on the literature survey and our time

series work, we develop estimates of $\left(\alpha_{h}, \sigma_{h}\right)$ and calibrate the historical rate of medical

innovation. We then develop long term projections of medical spending under the assumption that the parameter values and the innovation rate hold into the future and compare our results to those obtained via the older methodology.

\subsection{Total PHC Share of GDP}

As a benchmark for our model simulations, we construct a notional projection of total PHC based on the GDP + 1 assumption, using a methodology similar to that which underlies the Medicare Board of Trustees' long term projections. Specifically, for the first 10 projection years our benchmark medical spending growth forecast is initially the same as the Centers for Medicare and Medicaid Services 10-year forecast. Then, starting with the $10^{\text {th }}$ projection year, the benchmark forecast is slowly phased to GDP +1 over the next 15 years. Between the $25^{\text {th }}$ and $75^{\text {th }}$ projection years, medical spending growth follows the GDP +1 pattern. After year 75 , medical spending grows at $G D P+0$. We also retain the Medicare Trustees' long term assumption that there will be no difference between medical sector and non-medical sector productivity growth. $^{12}$

Figure 4 illustrates three model simulations and the GDP +1 benchmark projection. Consistent with the GDP + 1 methodology, our simulations start with the CMS 10-year

\footnotetext{
${ }^{12}$ This assumption, which can be modified in our model, is based on the findings of the 2000 Medicare Technical Review Panel which concluded that: (1) official measures overstate the rate of medical price inflation, and (2) in the future market forces will cause medical price inflation to be more in line with general price inflation. "The Panel believes that better control of prices by public and private payers, along with properly measured price indices, will result in future increases in health care prices that approximate wage and price growth in the overall economy. Currently, the use of conventional health care price indices gives an overly pessimistic view of productivity gains in medical care." Technical Review Panel on the Medicare Trustees Reports. "Review of Assumptions and Methods of the Medicare Trustees' Financial Projections. “December 2000. p 41.
} 
projection and then are gradually phased to the model forecast. The simulations and the benchmark projection are all targeted to a steady-state growth path implied by the Social Security program's long term assumptions, and all projections reflect a common age-gender adjustment. ${ }^{13}$ Table 5 summarizes the results and shows the projected PHC share of GDP in 2080 under alternative projections.

Our intermediate projection assumes parameter values $\left(\alpha_{h}, \sigma_{h}\right)=(0.9,0.4)$-consistent with our UCM equation 1 (Table 5) and with the average price elasticity in the literature (-0.45). Under the intermediate projection, PHC reaches about 35 percent of GDP in 2080 compared to 41 percent under $G D P+1$. The model also projects a more plausible transition path than that implied by $G D P+1$. In the near term, our projection calls for a larger differential between medical spending growth and GDP growth relative to GDP +1 (approximately 2 percentage points) that gradually falls over time. This is pattern is more consistent with recent historical experience and with the CMS 2015 projection.

The intermediate projection is compared to "high" and "low" paths that reflect different assumptions about the price elasticity of the demand for medical care; which in turn reflect the underlying health production technology and preferences for health relative to other forms of consumption. The low path assumes a price elasticity of approximately -0.7 that is closer to the international results and implies a stronger rationing effect. The high path assumes a price elasticity of about -0.2 , consistent with the low end of the range of estimates (such as the Rand HEI).

\footnotetext{
${ }^{13}$ CMS computes an age-gender index only to 2015 . We developed an index using a similar methodology based on medical consumption data compiled by Keehan, et al. (2005) from the Medical Expenditure Panel Survey (MEPS) and population projections from the Social Security Administration. Our index is consistent with the CMS index for the historical period over which CMS constructs its index (see figure 5).
} 
The high and low paths effectively set upper and lower bounds for the range of plausible long term projections of health care spending based on the empirical literature and the set of feasible parameters, with several caveats. First, our model does not have an endogenous explanation for the development of new medical technologies. The constraint on the future share growth of medical care, then, is on the demand-side reflecting limits on the degree to which new treatments are adopted. Concrete examples of this concept include limits on insurance coverage for new treatments (e.g., by limiting the populations which are eligible for coverage or by denying coverage altogether), and provisions for greater consumer cost-sharing. ${ }^{14}$ Second, the degree to which innovation is cost-increasing is fixed in the projection. It is plausible that increasing cost pressure will shift this relationship in the future, pushing technological innovation to new, less expensive replacements for older therapies. Finally, as noted earlier, the model neglects non-medical inputs to health. Higher medical costs, combined with greater public awareness of the relationship between lifestyle and future health, may lead to behavioral changes that result in better health with a slower rate of medical spending growth.

\subsection{Medicare Actuarial Balance}

One of the key uses of long term medical spending projections is to evaluate the long term financial and actuarial condition of the Medicare Hospital Insurance program. Typically, the status of the program is characterized by the actuarial balance, defined as the difference between average income and cost rates for a given period. In the case of an actuarial deficit, this difference can be interpreted as the number of percentage points by which the payroll tax rate

\footnotetext{
${ }^{14}$ As noted above, our model does not explicitly model the insurance choice decision, but posits that long run medical consumption must be consistent with household preferences for non-medical consumption.
} 
must be raised (or cost rates must be lowered) in order to resolve the program imbalance over the valuation period.

Table 6 shows that, while the PHC-GDP share generated by our intermediate assumption is ultimately lower than that implied by $G D P+1$, the actuarial deficits of the Medicare program implied by our intermediate path versus the $G D P+1$ assumption are about the same. However, Figure 4 shows that over time we would expect that projected deficits generated by the two methods would diverge. Under the $G D P+1$ procedure, medical spending net of demographic effects grows one percent faster than GDP until the $76^{\text {th }}$ projection year, when it reverts to GDP +0 . For every successive Trustees' Report, then, the $76^{\text {th }}$ projection year advances by one year, so the actuarial deficit is mechanically ratcheted up each year. In our model, preferences for health and non-medical consumption are convex and medical expenditure growth (implicitly both public and private) approaches the rate of income growth in the long run.

\section{Summary and Conclusions}

The contributions of this paper are threefold. First, we introduce to the forecasting process a formal framework for considering the opportunity costs of higher levels of medical spending that takes into consideration the introduction of new medical treatments. Relative to

the GDP + 1 methodology, the model generates near- and intermediate-term growth trajectories that are more consistent with recent historical experience and the latest near term forecasts (which predict a medical-GDP growth differential of about 2 percent, adjusted for age and gender effects). In the long term, the model generates a smoothly declining growth rate differential that seems to be more reasonable than the GDP +1 step-function pattern. 
A second contribution is that the model implicitly enforces consistency from a macroeconomic accounting perspective that is absent in GDP +1 . In our simulations, the level of medical spending must be consistent with assumptions about government consumption, investment, the consumption of non-medical goods and services, and the production of nonmedical inputs that are used to create medical care. Given the Social Security Administration's official long run economic growth forecast, different assumptions about medical expenditure growth must be reconciled with other sectors of the economy.

Third, our framework can be expanded to include more complicated feedback effects between the medical sector and the rest of the economy. For example, although in our baseline simulations we peg the rate of economic growth to the official long term projections of the Social Security program (for comparability with official projections), our model has the capability to analyze the implications of higher levels of medical spending, and concomitant increases in government expenditures, on economic growth. It is also feasible, in this framework to include the effects of health status on labor productivity, and intergenerational accounting issues (which we hope to explore in future articles).

Projections of medical care spending have taken a central place in discussions of economic policy. In the private sector, medical spending obligations to current and retired workers are placing increasing strains on the ability of U.S. businesses to compete in the international marketplace. In the public sector, long term projections of government-financed medical care are raising fundamental questions about the viability of such programs. Our hope is that this model is a useful starting point for more sophisticated approaches to understanding the long run determinants of medical spending growth. 


\section{REFERENCES}

Ballard, Charles L.; Goddeeris, John H. 1999. "Financing Universal Health Care in the United States: A General Equilibrium Analysis of Efficiency and Distributional Effects." National Tax Journal, 52(1), pp. 31-51.

Berndt, Ernst R.; Cutler, David M.; Frank, Richard G.; Griliches, Zvi; Newhouse, Joseph P.; Triplett, Jack E. 2000. "Medical Care Prices and Output" in The Handbook of Health Economics, Volume 1. Culyer, Anthony J., Newhouse, Joseph P., eds. Elsevier Science B.V., pp. 119-180.

Borger, Christine, et al., "Health Spending Projections Through 2015: Changes on the Horizon," Health Affairs, Web Exclusive, February 22, 2006.

Chernew, Michael E.; Hirth, Richard A.; Sonnad, Seema S.; Ermann, Rachel; Fendrick, Mark A. 1998. "Managed Care, Medical Technology, and Health Care Cost Growth: A Review of The Evidence." Medical Care Research and Review, 55(3), pp. 259-288.

Chernew, Michael E.; Hirth, Richard A.; Cutler, David M. 2003. "Increased spending in health care: How much can the United States Afford?” Health Affairs, 22(4), pp. 15-25.

Cutler, David M. 1995. Technology, Health Costs, and the NIH. Harvard University and the National Bureau of Economic Research. Paper prepared for the National Institutes of Health Economics Roundtable on Biomedical Research.

Cutler, David M.; and McClellan, Mark B. 1998. "What is Technological Change?" in Wise, David A., editor Inquiries in the Economics of Aging. National Bureau of Economic Research Project Report. MIT Press.

Cutler, David M.; and McClellan, Mark B. 2001. "Is Technological Change in Medicine Worth It?" Health Affairs, 20(5), pp. 11-29.

Ferris, Michael C.; Munson, Todd S. 2000. PATH Version 4.6, GAMS Development Corporation.

Follette, Glenn; and Sheiner, Louise. 2005. "The Sustainability of Health Spending Growth," Federal Reserve Board Staff Working Paper, 2005-60.

Fuchs, Victor R. 1996. "Economics, Values, and Health Care Reform," American Economic Review, 86, pp. 1-24.

Gerdtham, Ulf-G.; Jonsson, Bengt. 1991. "Price and Quantity in International Comparisons of Health Care Expenditure," Applied Economics, 23, pp. 1519-1528. 
Gerdtham, Ulf-G.; Jonsson, Bengt. 2000. "International Comparisons of Health Expenditure," in Handbook of Health Economics. Culyer, Anthony J., Newhouse, Joseph P., eds. Elsevier Science B.V., pp. 11-53.

Getzen, Thomas E., "Forecasting Health Expenditures: Short, Medium and Long (Long) Term." 2000. Journal Of Health Care Finance. 26(3), pp. 56-72.

Glied, Sherry A.; and Remler, Dahlia K. 2002. "What Every Public Finance Economist Needs to Know About Health Economics: Recent Advances and Unresolved Questions," National Tax Journal, 55(4), pp. 771-788.

Grossman, Michael, 1972. "On the Concept of Health Capital and the Demand for Health" The Journal of Political Economy, 80(2), pp. 223-255.

Grossman, Michael, 2000. "The Human Capital Model” in The Handbook of Health Economics, Volume 1A, Culyer, Anthony J., Newhouse, Joseph P., eds. Elsevier Science B.V., pp. 347-409.

Jones, Charles I. 2003. "Why Have Health Expenditures as a Share of GDP Risen So Much?" Department of Economics, U.C. Berkeley and NBER, Mimeo, July 24, 2003, version 2.10

Keehan, Sean; Lazenby, Helen; Zezza, Mark; Catlin, Aaron. 2004. "Age Estimates in the National Health Accounts." Draft dated August 19, 2004 (forthcoming in Health Care Financing Review).

Lau, Morten I.; Pahlke, Andreas; Rutherford, Thomas F. 2000. "Approximating InfiniteHorizon Models in a Complementarity Format: A Primer in Dynamic General Equilibrium Analysis.” January Draft. (The MobiDK Project, Danish Ministry of Trade and Industry).

Lau, Morten I.; Pahlke, Andreas; Rutherford, Thomas F. "Modelling Economic Adjustment: A Primer in Dynamic General Equilibrium Analysis," Journal of Economic Dynamics and Control, 2002, 26, pp. 577-609.

Manning, Willard G.; Newhouse, Joseph P.; Duan, Naihua; Keeler, Emmett B.; Leibowitz, Arleen; Marquis, Susan M. 1987. "Health Insurance and the Demand for Medical Care: Evidence from a Randomized Experiment." American Economic Review. 77(3), pp. 251-277.

Meltzer, David. "Can Medical Cost-Effectiveness Analysis Identify the Value of Research?” in Measuring the Gains from Medical Research, Kevin M. Murphy and Robert H. Topel eds. University of Chicago Press, 2003. pp 206-247.

Meltzer, David. 2001. "Theoretical Foundations of Medical Cost-Effectiveness Analysis." In Medical Care Output and Productivity, David M. Cutler and Ernst R. Berndt eds. National Bureau of Economic Research, Studies in Income and Wealth, Vol. 62. University of Chicago Press. 
Milne, R., and Molana, H.. 1991. "On the Effect of Income and Relative Price on Demand for Health Care: EC Evidence,” Applied Economics, 23, pp. 1221-1226.

Newhouse, Joseph P. 1988. "Has the Erosion of the Medical Market Place Ended?" Journal of Health Politics, Policy and Law, 13(2), pp. 263-278.

Newhouse, Joseph P; and the Insurance Experiment Group. 1993. Free for All? Leassons From the RAND Health Insurance Experiment. RAND and the Harvard University Press.

Nordhaus, William D. 2002. "The Health of Nations: The Contribution of Improved Health To Living Standards.” National Bureau of Economic Research. NBER Working Paper 8818.

Peden, Edgar A; and Freeland, Mark S. 1998 "Insurance Effects on US Medical Spending (19601993)." Health Economics, 7, pp. 671-687.

Ringel, Jeanne S.; Hosek, Susan D.; Vollaard, Ben A.; Mahnovski, Sergej. 2002. The Elasticity of Demand for Health Care A Review of the Literature and Its Application to the Military Health System. RAND report MR-1355-OSD.

Rutherford, Thomas F. 1999. "Applied General Equilibrium Modeling with MPSGE as a GAMS Subsystem: An Overview of the Modeling Framework and Syntax," Computational Economics, 14, pp. 1-46.

Technical Review Panel on the Medicare Trustees Reports. 2000. Review of Assumptions and Methods of the Medicare Trustees' Financial Projections, December. Sponsored by the Centers for Medicare and Medicaid Services (CMS--formerly, the Health Care Financing Administration)

Triplett, Jack E., 2001. "What's Different About Health?" In Medical Care Output and Productivity, David M. Cutler and Ernst R. Berndt eds. National Bureau of Economic Research, Studies in Income and Wealth, Vol. 62. University of Chicago Press. 2001

Warshawsky, Mark J., 1999. “An Enhanced Macroeconomic Approach to Long-Range Projections of Health Care and Social Security Expenditures as a Share of GDP." Journal of Policy Modeling, 21(4), pp. 413-426.

Weisbrod, Burton A. 1991. "The Health Care Quadrilemma: An Essay on Technological Change, Insurance, Quality of Care, and Cost Containment," Journal of Economic Literature, 24, pp. 523-552.

Wennberg, John E.; Fisher, Elliot S.; Skinner, Jonathan S. 2002. "Geography and the Debate Over Medicare Reform,” Health Affairs, Web Exclusive, February 13, 2002. 


\section{TABLES}

Table 1: Annualized Change in Real Quantity and Price Indexes, 1970-2004 (Source: U.S. Department of Commerce, Bureau of Economic Analysis)

\begin{tabular}{|c|c|c|c|c|c|}
\hline & \multicolumn{2}{|c|}{ PCE Real Quantity Index } & \multicolumn{2}{|c|}{ PCE Price Index } & \\
\hline & $\begin{array}{c}\text { Annual } \\
\text { Change } \\
\text { 1970-2004 }\end{array}$ & $\begin{array}{c}\text { Growth Diff: } \\
\text { Subcategory - } \\
\text { Total PCE }\end{array}$ & $\begin{array}{c}\text { Annual } \\
\text { Change } \\
\text { 1970-2004 }\end{array}$ & $\begin{array}{l}\text { Growth Diff: } \\
\text { Subcategory - } \\
\text { Total PCE }\end{array}$ & \\
\hline Personal consumption & 3.38 & 0.00 & 4.23 & 0.00 & \\
\hline Durable goods & & & & & \\
\hline Motor vehicles and parts & 4.48 & 1.10 & 3.08 & -1.16 & \\
\hline Furniture and household equipment & 7.30 & 3.92 & -0.30 & -4.53 & \\
\hline Other & 5.17 & 1.80 & 2.75 & -1.49 & \\
\hline Nondurable goods & & & & & \\
\hline Food & 1.91 & -1.47 & 4.28 & 0.04 & \\
\hline Clothing and shoes & 4.71 & 1.34 & 1.07 & -3.16 & \\
\hline Gasoline, fuel oil, and other & 1.28 & -2.10 & 5.49 & 1.26 & \\
\hline Other & 3.22 & -0.16 & 4.26 & 0.03 & \\
\hline Services & & & & & \\
\hline Housing & 2.88 & -0.50 & 4.81 & 0.58 & \\
\hline Household operation & 3.12 & -0.26 & 4.28 & 0.05 & \\
\hline Transportation & 2.86 & -0.52 & 4.79 & 0.55 & \\
\hline Medical care & 3.96 & 0.58 & 5.99 & 1.76 & $* * *$ \\
\hline Recreation & 5.29 & 1.91 & 4.09 & -0.14 & \\
\hline Other & 3.44 & 0.06 & 5.01 & 0.78 & $* * *$ \\
\hline
\end{tabular}

Table 1 shows annualized growth in the PCE real quantity indexes and price indexes by type of product between 1970 and 2004 (BEA Tables 2.4.3 and 2.4.4, respectively). Medical Care and Other Services are the only categories for which: (i) real growth exceeded total PCE growth, and (ii) price inflation was faster than total PCE price inflation. 
Table 2. Exogenous Parameters

\begin{tabular}{|c|c|c|}
\hline Parameter & Definition & Value \\
\hline$\rho$ & Discount Rate & $\frac{1+r}{(1+g)^{1-\theta}}-1$ \\
\hline$r$ & Annual interest rate & 0.04 \\
\hline$g$ & Economic growth rate & $\begin{array}{l}\text { Social Security Trust Fund } \\
\text { Intermediate Assumption }\end{array}$ \\
\hline$\theta$ & $\begin{array}{l}\text { Intertemporal elasticity of } \\
\text { substitution }\end{array}$ & 0.5 \\
\hline$\sigma_{u}$ & $\begin{array}{c}\text { Intratemporal elasticity of } \\
\text { substitution }\end{array}$ & 0.2 \\
\hline$\alpha_{h}$ & $\begin{array}{l}\text { Health production function } \\
\text { technology share parameter }\end{array}$ & 0.9 (baseline) \\
\hline$\sigma_{h}$ & $\begin{array}{l}\text { Health production function elasticity } \\
\text { of substitution }\end{array}$ & 0.4 (baseline) \\
\hline$\delta_{K}$ & Capital depreciation rate & 0.07 \\
\hline $\bar{H}, \bar{C}$ & $\begin{array}{l}\text { Linear expenditure system offset } \\
\text { parameters }\end{array}$ & 0.0 (baseline) \\
\hline
\end{tabular}


Table 3: Selected Price Elasticities ${ }^{15}$

\begin{tabular}{c|c|c}
\hline \hline Study & Data/Population & Elasticity \\
\hline \hline Feldstein, 1971 & AHA survey, 1958-1967; NCHS survey, 1963-1964 & -0.49 \\
Fuchs and Kramer, 1972 & 1966 IRS tabulations & -0.10 to -0.36 \\
Scitovsky and Snyder, 1972 & Palo alto Group Health Plan 1966-1968 \\
Rosett and Huang, 1973 & Survey of Consumer Expenditures, 1960 & -0.14 \\
Beck, 1974 & Sample of low-income people in Saskatchewan, Canada & -0.07 \\
Phelps, and Newhouse, 1974 & Insurance plans in the U.S., United Kingdom, and Canada & -1.5 \\
Scitovsky and McCall, 1977 & Palo Alto Group Health Plan, 1968-1972 & -0.04 to -0.12 \\
Wedig, 1988 & NMCUES, 1980 & -0.29 \\
Cherkin et al., 1989 & Group Health Cooperative of Puget Sound & -0.16 to -0.35 \\
R. Milne, H. Molana (1991) & 11 European Community countries, 1980 and 1985 & -0.04 \\
Gerdtham and Jonsson & 22 OECD countries, 1985 & -0.73 \\
Newhouse et al., 1993 & RAND NIE & -0.84 \\
Eichner, 1998 & Insurance claims, those covered through a large employer & -0.62 to -0.75 \\
\hline \hline
\end{tabular}

${ }^{15}$ All studies with the exception of Milne/Molana and Gerdtham/Jonsson from: Jeanne S. Ringel, et al., The Elasticity of Demand for Health Care A Review of the Literature and Its Application to the Military Health System. RAND report MR-1355-OSD 2002. 
Table 4: Selected Income Elasticities (v)

[From Getzen (2000) and Gerdtham and Jonsson (2000)]

\begin{tabular}{|c|c|c|c|c|c|}
\hline Study & Data & $v$ & Study & Data & $v$ \\
\hline Newhouse, Phelps 1976 & & $<0.1$ & Newhouse 1977 & 13 countries 1972 & 1.3 \\
\hline AMA 1978 & & $\approx 0$ & Maxwell 1981 & 10 countries 1975 & 1.4 \\
\hline Sunshine, Dicker 1987 & NMCUES & $\approx 0$ & Parkin, et al. 1987 & 24 OECD 1980 & 0.9 \\
\hline Manning et al. 1987 & RAND & $\approx 0$ & Gertler, vanderGaag 1990 & 25 countries 1975 & 1.2 \\
\hline Wedig 1988 & NMCUES & $\approx 0$ & Getzen 1990 & U.S. 1966-1975 & 1.6 \\
\hline Wagstaff et al. 1991 & & $\approx 0$ & Shieber 1990 & 7 countries $1960-1987$ & 1.2 \\
\hline Hahn, Lefkowitz 1992 & NMES & $\approx 0$ & Gerdtham et al. 1992 & 19 countries 1987 & 1.3 \\
\hline Feldstein 1971 & 47 states $1958-1967$ & 0.5 & Getaen, Poullier 1992 & 19 countries $1965-1986$ & 1.4 \\
\hline Fuchs, Kramer 1972 & 33 states 1966 & 0.9 & Hitiris, Posnett 1992 & 20 OECD 1960-1987 & $\begin{array}{c}1.0- \\
1.2\end{array}$ \\
\hline Levit 1982 & 50 states 1966 total & 0.9 & Gerdtham 1992 & 22 OECD 1972-1987 & 0.7 \\
\hline McLauglin 1987 & 25 SMSAs 1972-1982 & 0.7 & Viscusi (1994) & 24 OECD 1960-1989 & 1.1 \\
\hline Baker 1997 & US counties 1986-1990 & 0.8 & Blomqvist, Carter 1997 & 22 OECD 1970-1991 & $<1.0$ \\
\hline DiMatteo-DiMatteo 1998 & 10 Can. prov. $1965-1991$ & 0.8 & Gerdtham, et al. 1998 & 22 OECD 1970-1991 & $<1.0$ \\
\hline Abel-Smith 1967 & 33 countries, 1961 & 1.3 & Barros 1998 & 24 OECD 1960-1991 & $<1.0$ \\
\hline Kleiman 1974 & 16 countries 1968 & 1.2 & Roberts 1998 & 20 OECD 1960-1993 & $>1.0$ \\
\hline
\end{tabular}


Table 5. Unobserved Component Model (UCM) Estimation Results

\begin{tabular}{|c|c|c|c|c|}
\hline Equation & 1 & 2 & 3 & 4 \\
\hline Dependent Variable & $\begin{array}{l}\text { NPHC60- } \\
\text { MNGDP60 }\end{array}$ & $\begin{array}{l}\text { NPHC60- } \\
\text { MNDPI60 }\end{array}$ & NPHC60 & NPHC60 \\
\hline Income Variable & & & MNDPI60 & MNGDP60 \\
\hline Price Variable & PGDP-PPHC & PDPI-PPHC & PDPI-PPHC & PGDP-PPHC \\
\hline Sample & 1960-2004 & 1960-2004 & 1960-2004 & $1960-2004$ \\
\hline Durbin-Watson & 1.82 & 1.72 & 1.76 & 1.87 \\
\hline $\begin{array}{l}\mathbf{R}^{2} \\
\text { Coefficients }\end{array}$ & 0.45 & 0.39 & 0.69 & 0.67 \\
\hline Income & & & 0.92 & 0.74 \\
\hline Price & 0.39 & 0.41 & 0.41 & 0.42 \\
\hline RMSE & & & & \\
\hline Income & & & 0.20 & 0.19 \\
\hline $\begin{array}{c}\text { Price } \\
T-\text { Vlue }\end{array}$ & 0.17 & 0.13 & 0.13 & 0.17 \\
\hline $\begin{array}{l}\text { 1-Value } \\
\text { Income }\end{array}$ & & & 4.65 & 3.88 \\
\hline Price & 2.31 & 3.25 & 3.18 & 2.48 \\
\hline Estimated $\sigma_{h}$ & 0.39 & 0.41 & & \\
\hline Estimated $\operatorname{Exp}\left[\mu_{1}\right]$ & -3.09 & -2.73 & & \\
\hline Computed $\alpha_{h}$ & 0.89 & 0.52 & & \\
\hline
\end{tabular}


Table 6: Simulation Results

\begin{tabular}{c|c|c|c|c}
\hline \hline & $G D P+1$ & Intermediate & High & Low \\
\hline \hline$\alpha_{\mathrm{h}}$ & -- & 0.90 & 0.95 & 0.60 \\
$\sigma_{\mathrm{h}}$ & -- & 0.40 & 0.20 & 0.45 \\
Calibrated $g_{z}$ & -- & $6.3 \%$ & $5.0 \%$ & $9.6 \%$ \\
Reference Period $\eta$ & -- & -0.45 & -0.24 & -0.67 \\
2080 PHC-GDP Share & $41 \%$ & $35 \%$ & $45 \%$ & $24 \%$ \\
2080 Actuarial Deficit & $-3.50 \%$ & $-3.48 \%$ & $-4.56 \%$ & $-2.24 \%$ \\
\hline \hline
\end{tabular}




\section{FIGURES}

\section{Figure 1. Functional Forms}
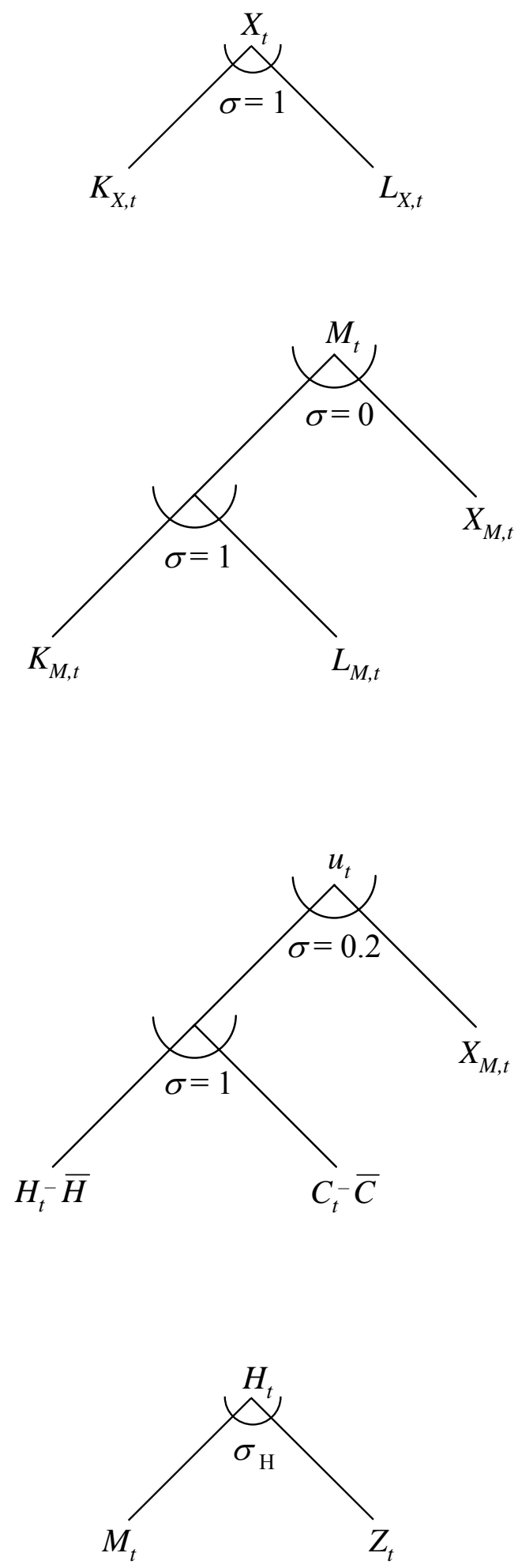

Cobb-Douglas production function for non-medical goods and services.

Nested production function for medical goods and services. Nonmedical input and value added: fixed coefficient. Capital and labor input: Cobb-Douglas.
Nested utility function over health, consumption and leisure. Constant intertemporal elasticity of substitution. Intratemporal utility: linear expenditure system. 
Figure 2. PHC Share of GDP Under Different Combinations of $\alpha_{h}$ and $\sigma_{h}$ (Net of Growth Due to Demographics)

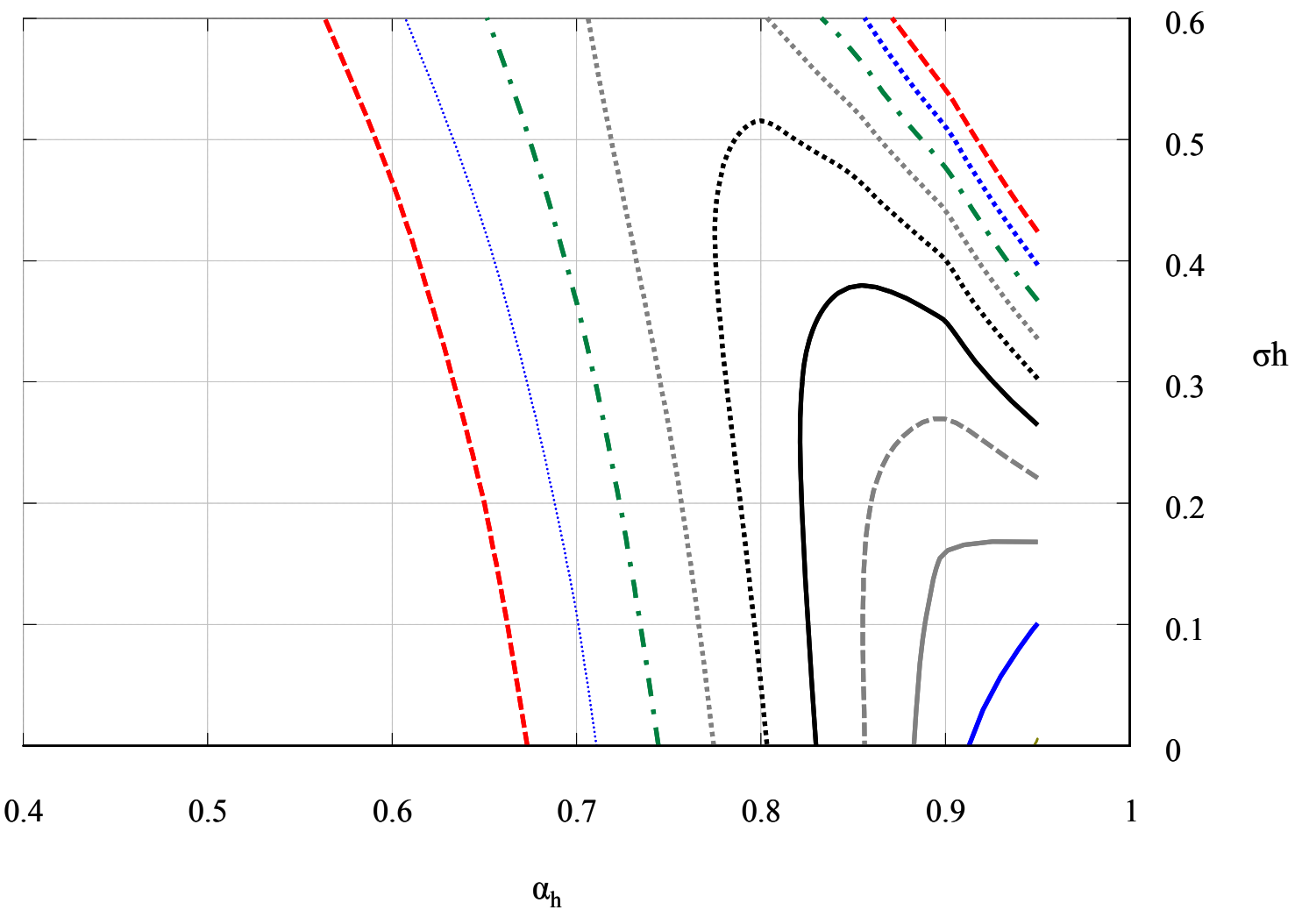

0.20

0.22

$0.24-\cdot-\cdot-$

0.26

0.28

$0.30 \longrightarrow$

0.32 -ோ・ோー

$0.34-$

0.36

0.38 
Figure 3. PHC Growth Relative to GDP Growth Under Alternative $\sigma_{h}$ Assumptions $\left(\alpha_{h}=\mathbf{0 . 9 5}\right)$

Vertical Axis: Annual Percentage Point Difference, PHC Growth - GDP Growth

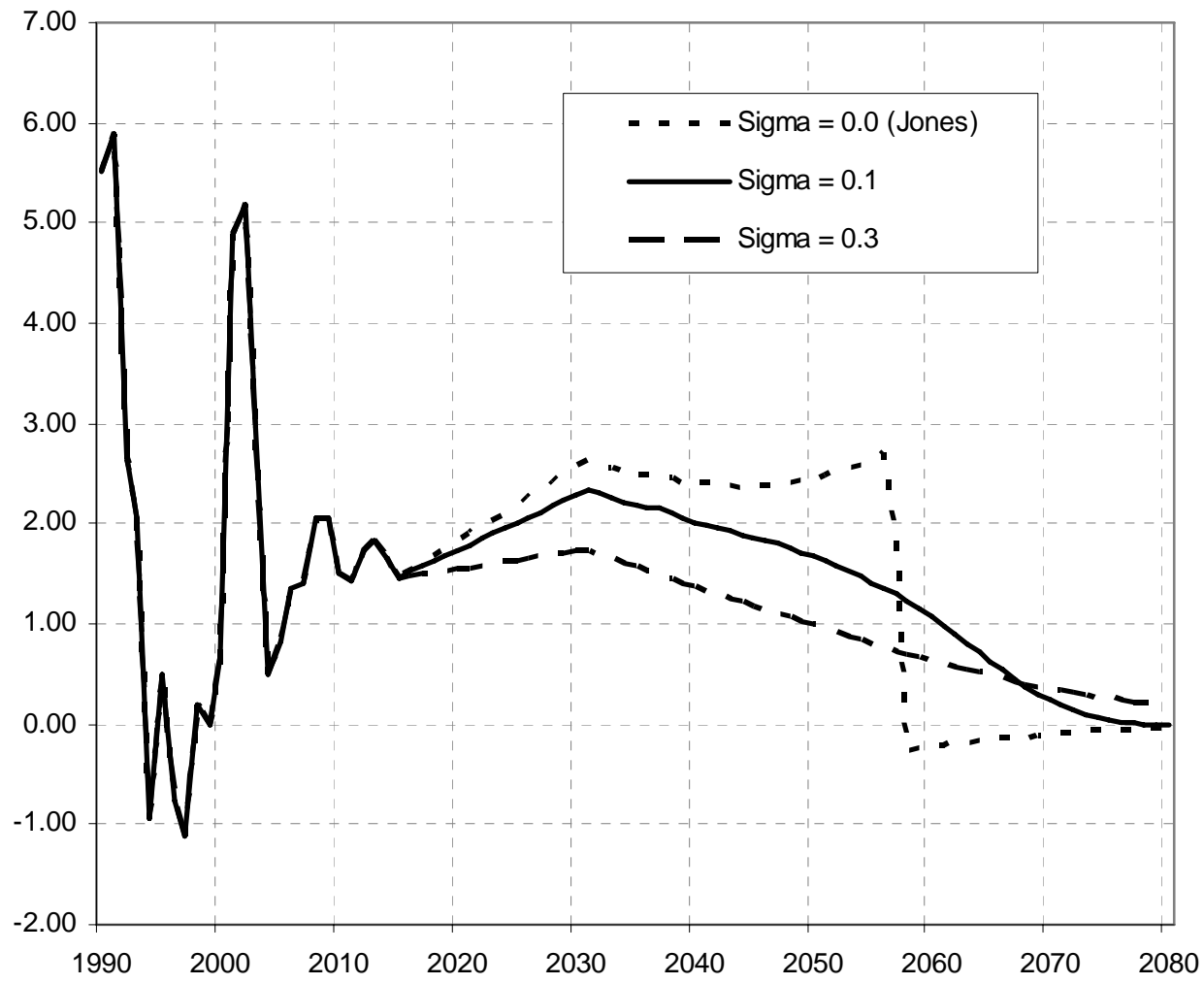


Figure 4. PHC as a Share of GDP

(Inclusive of Growth Attributable to Demographic Effects)

Vertical Axis: Share of GDP

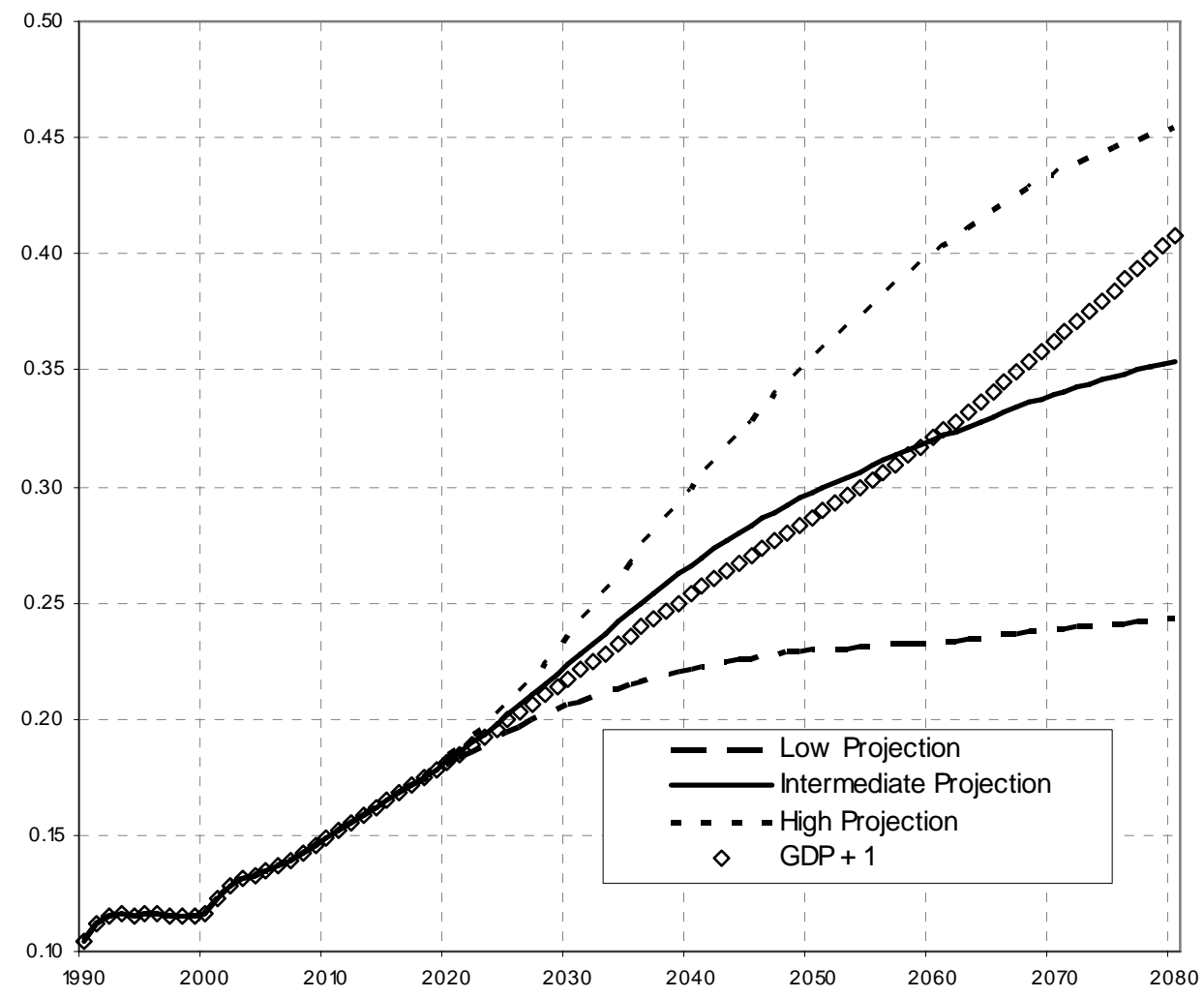


Figure 5. CMS Age-Gender Factors v.

Age-Gender Factors Computed by the Authors

Vertical Axis: Annual Percent Change

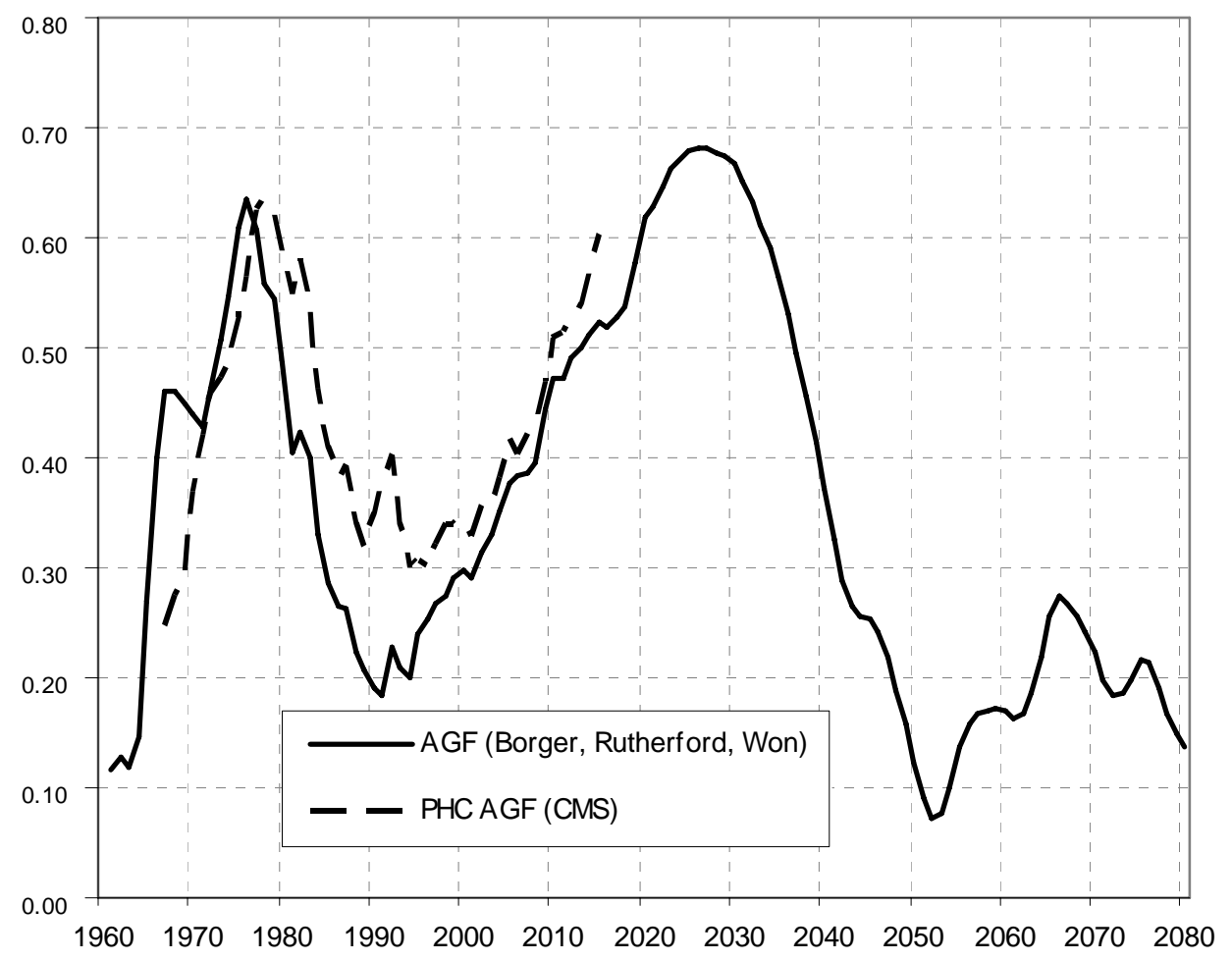




\section{BACKGROUND INFORMATION FOR REVIEWERS (NOT INTENDED FOR PUBLICATION)}

\section{Solving the Intertemporal General Equilibrium Model}

Our model is approximated as a finite-dimensional nonlinear complementarity problem using the PATH solver (Ferris and Munson, 2000). The equations of the model are implemented using the Mathematical Programming System for General Equilibrium (MPSGE, Rutherford, 1999). This section of the paper discusses some of the issues involved in approximating the infinite horizon, as has been described in Lau et al. (2002).

Intertemporal preferences are based on the intertemporal elasticity of substitution, the base year consumption level, the baseline equilibrium index of economic activity calculated on the basis of the long-run steady-state growth rate, and the baseline present value price path calculated on the basis of a steady-state interest rate. The discount rate is defined implicitly as:

$$
\rho=\frac{1+\bar{r}}{(1+g)^{1-\vartheta}}-1
$$

In order to solve a finite approximation of the model with a $T$-period model horizon, we need to decompose the consumer's problem. Consider the infinite-horizon problem of the representative agent:

$$
\max \sum_{t=0}^{\infty}\left(\frac{1}{1+\rho}\right)^{t} u\left(c_{t}\right)
$$

s.t.

$$
\sum_{t=0}^{\infty} p_{t} c_{t}=p_{o}^{K} \bar{K}_{o}+\sum_{t=0}^{\infty} p_{t}^{L} \bar{L}_{t}
$$

Define a value of terminal assets to be: 


$$
A_{T}^{*}=\sum_{t=T+1}^{\infty}\left(p_{c} c_{t}^{*}-p_{t}^{L} \bar{L}_{t}\right)
$$

Then consider the equivalent model:

$$
\begin{gathered}
\max \sum_{t=0}^{T}\left(\frac{1}{1+\rho}\right)^{t} u\left(c_{t}\right)+\sum_{t=T+t}^{\infty}\left(\frac{1}{1+\rho}\right)^{t} u\left(c_{t}\right) \text { s.t } \\
\sum_{t=0}^{T} p_{t} c_{t}=p_{o}^{K} \bar{K}_{o}+\sum_{t=0}^{T} p_{t}^{L} \bar{L}_{t}-A_{T} \\
\sum_{t=T+1}^{\infty} p_{t} c_{t}=A_{T}+\sum_{t=T+1}^{\infty} p_{t}^{L} \bar{L}_{t}
\end{gathered}
$$

If $A_{T}$ is fixed then this can be posed as two separate optimization problems, one running through time period $T$ and another for the post-terminal period. When terminal assets are assigned a value of $A_{T}^{*}$, corresponding to the infinite-horizon solution, then the finite horizon model will produce consumption levels for years 0 through $T$ which are identical to the $\infty$-horizon model.

Terminal assets in the closed economy are simply equal to the value of the capital stock at the start of period $T+1$. The model running through year $T$ then produces a good approximation to the consumer problem when we have a good approximation to the terminal capital stock. The key insight provided by Lau, Pahlke, and Rutherford (2000) is that the state variable $K_{\mathrm{T}+1}$ can be determined as part of the equilibrium calculation by targeting the associated control variable, $I_{\mathrm{T}}$. In the present model, this is based on a constraint relating the terminal investment growth rate to GDP growth rate: 


$$
\frac{I_{T}}{I_{T-1}}=1+g
$$

\section{Unobserved Components Model}

Under the assumptions of our model, the medical demand equation is:

$$
M=\alpha\left(1-\alpha_{h}\right) \frac{I}{P_{U}}\left(\frac{P_{U}}{P_{H}}\right)\left(\frac{P_{H}}{P_{M}}\right)^{\sigma_{h}}
$$

$\alpha_{h}$ and $\sigma_{h}$ are the reference period technology share of health output, and the elasticity of substitution between medical and technology inputs in the production of health, respectively. $\alpha$ is the health share of composite (health and nonmedical) consumption, which is determined from the technology share, $\alpha_{h}$, in equilibrium. We cannot simply estimate the log form of this equation because the unobserved health price appears in two terms: $\left(\frac{P_{U}}{P_{H}}\right)$ and $\left(\frac{P_{H}}{P_{M}}\right)$.

In log form, the medical demand equation can be written as:

$$
\ln (M)=\ln \left[\alpha\left(1-\alpha_{h}\right)\right]+\ln \left(\frac{I}{P_{U}}\right)+\ln \left(P_{U}\right)-\ln \left(P_{H}\right)+\sigma_{h} \ln \left(P_{H}\right)-\sigma_{h} \ln \left(P_{M}\right)
$$

Add zero to the right-hand-side by adding and subtracting $\sigma_{H} \ln \left(P_{U}\right)$.

$$
\ln (M)=\ln \left[\alpha\left(1-\alpha_{h}\right)\right]+\ln \left(\frac{I}{P_{U}}\right)+\sigma_{h} \ln \left(\frac{P_{U}}{P_{M}}\right)+\ln \left(\frac{P_{U}}{P_{H}}\right)-\sigma_{h}\left[\ln \left(P_{U}\right)-\ln \left(P_{H}\right)\right]
$$




$$
\ln (M)=\ln \left[\alpha\left(1-\alpha_{h}\right)\right]+\ln \left(\frac{I}{P_{U}}\right)+\left(1-\sigma_{h}\right) \ln \left(\frac{P_{U}}{P_{H}}\right)+\sigma_{h} \ln \left(\frac{P_{U}}{P_{M}}\right)
$$

Or,

$$
\ln \left(\frac{M_{t}}{I_{t} / P_{U}}\right)=\mu_{t}+\delta \ln \left(\frac{P_{U t}}{P_{M t}}\right)
$$

where

$$
\mu_{t}=\ln \left[\alpha\left(1-\alpha_{h}\right)\right]+\left(1-\sigma_{h}\right) \ln \left(\frac{P_{U t}}{P_{H t}}\right)
$$

To compute estimates of the key model parameters $\alpha_{h}$ and $\sigma_{h}$ we use an unobserved components model (UCM) also called a structural time series model (Harvey, 1989).

$$
\begin{array}{cc}
y_{t}=\mu_{t}+\boldsymbol{X}_{t}^{\prime} \boldsymbol{\delta}+\varepsilon_{t}, & \varepsilon_{t} \sim \operatorname{NID}\left(0, \sigma_{\varepsilon}^{2}\right) \\
\mu_{t}=\mu_{t-1}+\beta_{t-1}+\eta_{t}, & \eta_{t} \sim N I D\left(0, \sigma_{\eta}^{2}\right) \\
\beta_{t}=\beta_{t-1}+\xi_{t}, & \xi_{t} \sim N I D\left(0, \sigma_{\xi}^{2}\right)
\end{array}
$$

Where $y_{t}$ is the dependent variable, $\boldsymbol{X}_{t}$ are explanatory variables, $\boldsymbol{\delta}$ are the parameters associated with $\boldsymbol{X}_{t}$, and $\mu_{t}$ and $\beta_{t}$ are unobserved level and slope components that slowly change the relationship between $y$ and $\boldsymbol{X}$ over time. The unobserved components are estimated from the observations using the Kalman filter (table D shows the data we used to estimate our model). 
We used STAMP—Structural Time Series Analyzer, Modeller, and Predictor (Koopman, Harvey, Doornik, Shephard, 2000) to estimate the model. The coefficient associated with the relative medical price term $\left(\frac{P_{U t}}{P_{M t}}\right)$ is an estimate of the health production function elasticity of substitution. On the other hand, $\alpha_{h}$ cannot be directly determined from the model estimation. However, the UCM results imply a relation between $\alpha$ and $\alpha_{h}$ that can be used, together with other information, to calculate an estimate of $\alpha_{h}$.

$\mu_{t}$ is a level component that reflects the benchmark period health share of consumption, and the slope component, $\beta_{t}$, is a measure of the change in the relative price of health over time. However, we are only interested in the initial unobserved level component. If all prices are normalized to 1 in the initial year (in this case 1960), then the estimate of the $\mu_{1}$ gives us a relationship between $\alpha_{h}$ and $\alpha$.

$$
\exp \left(\mu_{1}\right)=\left[\alpha\left(1-\alpha_{h}\right)\right]
$$

Our model's utility and production functions also imply a reference period relationship between $\alpha_{h}$ and $\alpha$, given by:

$$
\alpha=\frac{\bar{C}}{\bar{C}+\left(\frac{\bar{M}}{1-\alpha_{h}}\right)}
$$

Where the bars above the variables indicate benchmark year values. Although we cannot measure $Z$, the level of medical knowledge, our assumption about $\alpha_{h}$, the reference period technology share of health, determines $Z$ and hence determines the reference period level of 
health output. This, in turn, determines the reference period health share of consumption, $\alpha$. So one method to construct estimates of $\alpha$ and $\alpha_{h}$ is to select those combinations that simultaneously solve equation B.8 and B.9. Figure B.1 shows such a point, given a 1960 benchmark year and $\exp \left(\mu_{1}\right)=0.065$ (corresponding to the results from UCM equation 4).

\section{Figure B.1: Plots of equations B.8 and B.9}

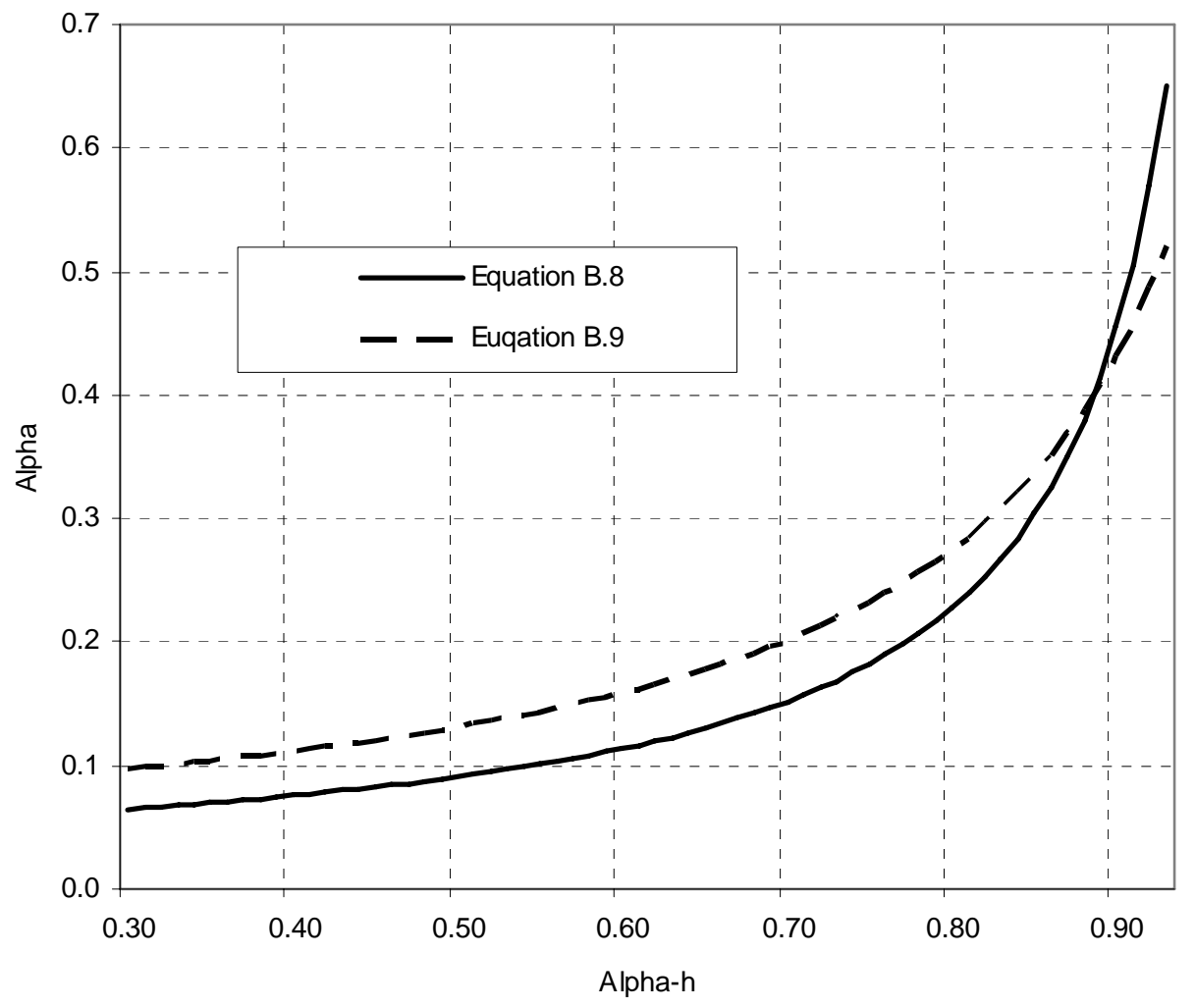


Table B.1. Unobserved Components Model Data

\begin{tabular}{|c|c|c|c|c|c|c|}
\hline & NPHC60 & MNGDP60A & MNDPI60A & РPHC60 & PGDP60A & PDPI60A \\
\hline 1960 & 4.83030 & 7.91933 & 7.56041 & 0.00000 & 0.00000 & 0.00000 \\
\hline 1961 & 4.85858 & 7.92753 & 7.57029 & 0.01521 & 0.01118 & 0.01065 \\
\hline 1962 & 4.89675 & 7.94518 & 7.58644 & 0.03544 & 0.02472 & 0.02212 \\
\hline 1963 & 4.95276 & 7.97338 & 7.60847 & 0.05364 & 0.03526 & 0.03383 \\
\hline 1964 & 5.00655 & 8.00014 & 7.63679 & 0.08147 & 0.05048 & 0.04806 \\
\hline 1965 & 5.04835 & 8.03527 & 7.67271 & 0.10796 & 0.06858 & 0.06256 \\
\hline 1966 & 5.08945 & 8.07935 & 7.71313 & 0.15748 & 0.09668 & 0.08739 \\
\hline 1967 & 5.15766 & 8.11727 & 7.75342 & 0.20527 & 0.12715 & 0.11244 \\
\hline 1968 & 5.21540 & 8.15679 & 7.79571 & 0.26100 & 0.16893 & 0.15102 \\
\hline 1969 & 5.26877 & 8.19176 & 7.83101 & 0.31864 & 0.21733 & 0.19579 \\
\hline 1970 & 5.32165 & 8.21454 & 7.86281 & 0.38040 & 0.26890 & 0.24191 \\
\hline 1971 & 5.34454 & 8.23133 & 7.89301 & 0.44066 & 0.31773 & 0.28358 \\
\hline 1972 & 5.40043 & 8.25343 & 7.92387 & 0.47941 & 0.36024 & 0.31762 \\
\hline 1973 & 5.46431 & 8.27803 & 7.95966 & 0.51742 & 0.41452 & 0.37060 \\
\hline 1974 & 5.50516 & 8.29546 & 7.98728 & 0.60508 & 0.50101 & 0.46904 \\
\hline 1975 & 5.52999 & 8.31246 & 8.01185 & 0.70759 & 0.59115 & 0.54896 \\
\hline 1976 & 5.56978 & 8.33424 & 8.03625 & 0.79195 & 0.64732 & 0.60299 \\
\hline 1977 & 5.60901 & 8.35547 & 8.05881 & 0.86747 & 0.70893 & 0.66579 \\
\hline 1978 & 5.63964 & 8.37668 & 8.07773 & 0.94335 & 0.77687 & 0.73368 \\
\hline 1979 & 5.67300 & 8.40441 & 8.10226 & 1.03002 & 0.85647 & 0.81813 \\
\hline 1980 & 5.70221 & 8.43067 & 8.12397 & 1.13788 & 0.94330 & 0.91947 \\
\hline 1981 & 5.72415 & 8.45136 & 8.14289 & 1.25318 & 1.03309 & 1.00486 \\
\hline 1982 & 5.72635 & 8.45898 & 8.15886 & 1.35464 & 1.09230 & 1.05871 \\
\hline 1983 & 5.74203 & 8.46473 & 8.17227 & 1.42710 & 1.13110 & 1.10088 \\
\hline 1984 & 5.75198 & 8.47867 & 8.19599 & 1.49982 & 1.16796 & 1.13798 \\
\hline 1985 & 5.76922 & 8.50137 & 8.22379 & 1.56969 & 1.19794 & 1.17047 \\
\hline 1986 & 5.79533 & 8.52598 & 8.25240 & 1.61755 & 1.21973 & 1.19456 \\
\hline 1987 & 5.82823 & 8.56038 & 8.27983 & 1.66524 & 1.24667 & 1.22867 \\
\hline 1988 & 5.86414 & 8.59403 & 8.30914 & 1.72553 & 1.28023 & 1.26749 \\
\hline 1989 & 5.88703 & 8.62101 & 8.32967 & 1.79212 & 1.31736 & 1.31019 \\
\hline 1990 & 5.92130 & 8.64306 & 8.34685 & 1.85717 & 1.35524 & 1.35495 \\
\hline 1991 & 5.94992 & 8.65708 & 8.35809 & 1.91204 & 1.38962 & 1.39060 \\
\hline 1992 & 5.96623 & 8.67025 & 8.37177 & 1.96338 & 1.41234 & 1.41902 \\
\hline 1993 & 5.97076 & 8.67999 & 8.37851 & 2.00921 & 1.43518 & 1.44184 \\
\hline 1994 & 5.97290 & 8.69038 & 8.38474 & 2.04628 & 1.45621 & 1.46268 \\
\hline 1995 & 5.98320 & 8.70194 & 8.39264 & 2.08270 & 1.47648 & 1.48390 \\
\hline 1996 & 5.99510 & 8.72140 & 8.40572 & 2.11208 & 1.49526 & 1.50520 \\
\hline 1997 & 6.01501 & 8.74362 & 8.41948 & 2.13336 & 1.51175 & 1.52191 \\
\hline 1998 & 6.03299 & 8.76904 & 8.44301 & 2.15518 & 1.52278 & 1.53086 \\
\hline 1999 & 6.05038 & 8.79551 & 8.46697 & 2.18196 & 1.53715 & 1.54737 \\
\hline 2000 & 6.07078 & 8.82416 & 8.49513 & 2.21518 & 1.55870 & 1.57191 \\
\hline 2001 & 6.10633 & 8.84689 & 8.52109 & 2.25276 & 1.58241 & 1.59262 \\
\hline 2002 & 6.13816 & 8.86443 & 8.54654 & 2.29035 & 1.59973 & 1.60672 \\
\hline 2003 & 6.16709 & 8.87964 & 8.56589 & 2.32647 & 1.61984 & 1.62564 \\
\hline 2004 & 6.19343 & 8.89499 & 8.58641 & 2.36658 & 1.64578 & 1.65113 \\
\hline
\end{tabular}

